\title{
Transvaginal Ultrasound for Endometrial Carcinoma Screening - Current Evidence-based Data
}

\author{
Transvaginaler Ultraschall zum Screening auf Endometriumkarzinome - \\ Evidenz-basierte Datenlage
}

Authors

Affiliations
E. Steiner, I. Juhasz-Bösz, G. Emons, H. Kölbl, R. Kimmig, P. Mallmann, für die AGO Uterus der DGGG

The affiliations are listed at the end of the article

\section{Key words \\ - transvaginal ultrasound \\ - endometrial cancer \\ - screening \\ Schlüsselwörter \\ - transvaginaler Ultraschall \\ - Endometriumkarzinom \\ - Screening}

\section{Abstract \\ $\nabla$}

The value of transvaginal ultrasound in gynaecological examinations is beyond dispute. But it is of particular forensic importance that the validity of this type of imaging with regard to the reliable detection of early-stage malignancy is properly understood. Vaginal ultrasound screening in asymptomatic patients for the early detection of endometrial carcinoma is not useful from a medical point of view, nor is it cost-efficient. However, even though the validity of transvaginal ultrasound for screening has currently not been proven, the method should still be an integral part of gynaecological examinations.

\section{Introduction}

$\nabla$

The value of transvaginal ultrasound in gynaecological examinations is beyond dispute. But it is of particular forensic importance that the validity of this type of imaging with regard to the reliable detection of early-stage malignancy is properly understood. The discussion about the validity of certain examinations is currently spearheaded by health insurance companies, and the ensuing publications frequently have an impact on counselling and patient care. Thus, in February of this year, the German Patients' Organisation “Unabhängige Patientenberatung Deutschland" (UPD) (www.unabhaengige-patientenberatung.de/) published a "consultation of the month" on their homepage on why they could not recommend ultrasound screening for the early detection of ovarian cancer. They quoted a study by the German Institute of Medical Documentation and Information (DIMDI) published in the summer of 2011, which investigated the available data on this individual healthcare service. The Unabhängige Patientenberatung Deutschland is a not-for-profit,

\section{Zusammenfassung \\ $\nabla$}

Die Wertigkeit der transvaginalen Ultraschalluntersuchung im Rahmen der gynäkologischen Untersuchung ist unbestritten. Es ist aber von besonderer auch forensischer Bedeutung, dass die Aussagekraft dieses Untersuchungsverfahrens im Hinblick auf das sichere Erkennen einer Krebserkrankung im Frühstadium sinnvoll eingeordnet wird. Unter Kosten-Nutzen-Gesichtspunkten ist ein generelles Screening bei asymptomatischen Patientinnen nicht sinnvoll. Zwar kann die transvaginale Sonografie das Ziel als Screeninginstrument zum gegenwärtigen Zeitpunkt nicht erreichen kann, sie bleibt aber integraler Bestandteil der gynäkologischen Untersuchung.

limited liability association of independent counselling centres all over Germany which was commissioned by the umbrella organisation for German statutory healthcare insurance to offer patient counselling to all insured patients as a standard service. This has affected the healthcare offered our patients because it has triggered an unnecessary discussion of an established, useful, and successful examination. Because transvaginal ultrasound is not suitable for screening, the utility of the examination in its entirety has been called into question. For routine counselling it is therefore important to know why transvaginal ultrasound is not a reliable method for early detection. This evidence-based information also has important forensic implications as it can prevent liability claims being made, based on an examination which cannot fulfil these claims. The validity of transvaginal ultrasound is not being called into question; that remains indisputable. The aim of this paper was to provide a rational overview of the current literature on the validity of transvaginal ultrasound in the screening of endometrial carcinoma. 


\section{Ultrasound in Asymptomatic Women ("Screening")} $\nabla$

At present, systematic ultrasound screening is not indicated for the early detection of endometrial carcinoma in asymptomatic women. The endometrium is usually examined incidentally during sonography for other indications (e.g. lower pelvic pain, hypogastric tumour, urogynaecology, etc.). Only a few studies have specifically focused on ultrasound screening of asymptomatic women and on the early detection of endometrial carcinoma. The largest study on this question to date was done in England [1]. In this study, carried out as a case-control study within the United Kingdom Collaborative Trial of Ovarian Cancer Screening (UKCTOCS), 48230 postmenopausal women underwent transvaginal ultrasound screening. The findings in 9078 women were excluded from the analysis of the validity of transvaginal sonography for the early detection of endometrial carcinoma as these women had undergone hysterectomy. In a further 2271 cases, the endometrial thickness was not recorded; of these only 157 cases with anomalies on sonography were included in the study. Measurement of endometrial thickness was done at the thickest point in the sagittal plane, from anterior to posterior; all ultrasound investigations were done by specially qualified colleagues. Follow-up data were obtained using the national registry of births and through questionnaires sent by post.

Endometrial carcinoma or atypical endometrial hyperplasia was diagnosed in 136 women one year or less after transvaginal sonography. The authors calculated an endometrial thickness of 5.15 as the ideal cut-off for the detection of carcinoma or hyperplasia. This resulted in a sensitivity of $80.5 \%$ and a specificity of $86.2 \%$.

A cut-off of $5 \mathrm{~mm}$ had a sensitivity of $80.5 \%$ and a specificity of $85.7 \%$. The corresponding figures for a cut-off of $10 \mathrm{~mm}$ were $54.1 \%$ and $97.2 \%$. The combination of endometrial thickness $\geq 5 \mathrm{~mm}$ and structural anomalies on ultrasound had a sensitivity of $85.3 \%$ and a specificity of $80.4 \%$.

When the analysis was confined to the 96 cases with carcinoma or hyperplasia diagnosed without a previous medical history of postmenopausal bleeding, the authors calculated a sensitivity of $77.1 \%$ and a specificity of $85.5 \%$.

In women in the high-risk group (who presented with a combination of weight gain, older age, concomitant breast cancer or other malignancies) the optimal cut-off was an endometrial thickness of $6.75 \mathrm{~mm}$, which had a sensitivity of $84.3 \%$ and a specificity of $89.9 \%$ [1].

While this study showed that transvaginal sonography had a high sensitivity, the data were not sufficient to warrant more general screening. Moreover, data on overall survival were lacking in this study. And the data also included a large number of unnecessary operative procedures. However, according to Jacobs et al. [1], when screening was limited to patients in the high-risk group, false-positive results were largely avoidable. These highrisk groups will be discussed in detail below. The data from the study of Jacobs et al. must, however, also be considered in the context of other studies. Thus, based on their theoretical study, Smith-Bindman et al. [2] recommended that endometrial biopsy in postmenopausal patients without vaginal bleeding only be done when patients had an endometrial thickness $>11 \mathrm{~mm}$, as the risk of endometrial carcinoma in this patient group was extremely low, a mere $0.002 \%$ for patients with an endometrial thickness $\leq 11 \mathrm{~mm}$.

The only study to our knowledge which investigated 5-year disease-free survival (DFS) in connection with the manner in which the endometrial carcinoma was detected, found no difference between patients investigated based on "findings at screening" (i.e., sonographically anomalous findings in otherwise asymptomatic patients) compared to symptomatic patients with postmenopausal bleeding of less than 8 weeks [3].

It should also be mentioned that the rates for endometrial carcinoma detected on autopsy were 4-6 times higher than the rates for endometrial carcinoma detected during patients' life times [4]. This shows that by no means all endometrial carcinomas are clinically evident or even life-threatening.

Schnell-Inderst et al. compiled a health technology assessment (HTA) report on "Individual Healthcare Services" on behalf of the "German Agency for HTA of the DIMDI" (German Institute of Medical Documentation and Information). This report also included a systematic review of the literature on the early detection of endometrial carcinoma using transvaginal ultrasound. Schnell-Inderst et al. showed that there is no data showing a reduction of mortality using transvaginal ultrasound screening for the early detection of endometrial carcinoma. They concluded that there is no evidence of any patient-relevant benefit from vaginal ultrasound screening for endometrial and ovarian carcinoma. In fact, more harm was done to patients through overdiagnosis, which led to unnecessary invasive procedures (Schnell-Inderst et al., HTA-Bericht 113, DIMDI).

\section{Ultrasound in Patients with Postmenopausal Bleeding $\nabla$}

The largest amount of data available on the validity of ultrasound screening for the early detection of endometrial carcinoma is on patients with postmenopausal bleeding [5-8]. Based on these data, the likelihood of developing endometrial carcinoma is lowest when the endometrial thickness, measured vaginally, is low. The cut-off for total endometrial thickness was between 3 and $5 \mathrm{~mm}$, depending on the study. Smith-Bindman et al. reported an endometrial carcinoma rate of $7.3 \%$ for an endometrial thickness $>5 \mathrm{~mm}$, while the rate of endometrial carcinoma for thicknesses $\leq 5 \mathrm{~mm}$ was only $0.07 \%$ [5]. A more recent study even discussed an endometrial thickness of $3 \mathrm{~mm}$ as the cut-off [8].

In asymptomatic women, Smith-Bindman et al. proposed using a cut-off for endometrial thickness of $11 \mathrm{~mm}$ in a theoretical cohort. The risk of developing carcinoma in women with an endometrial thickness $>11 \mathrm{~mm}$ would be $6.7 \%$ compared to $0.002 \%$ in women with an endometrial thickness $\leq 11 \mathrm{~mm}$ [5]. However, these data have not yet been validated in a prospective clinical study.

\section{Ultrasound in Postmenopausal Patients with HRT $\nabla$}

After menopause, hormone replacement therapy (HRT) affects endometrial thickness and the risk of developing endometrial carcinoma. Oestrogen-alone therapy increases the risk of endometrial carcinoma, while oestrogen-progestagen combination therapy with progestagen administered for at least 10 days, better 12 days, in every month of treatment does not increase the risk for endometrial carcinoma [9]. A large meta-analysis showed that the incidence of bleeding disorders and of endometrial hyperplasias was also significantly higher when HRT consisted of oestrogen alone [10]. The type of HRT is also important for the sonographic assessment of endometrial thickness. In a study by Van den Bosch et al., which included a total of 238 women, the 
average endometrial thickness in women receiving continuous combined oestrogen-progestagen HRT was $3.5 \pm 1.6 \mathrm{~mm}$, while endometrial thickness was $4.1 \pm 1.9 \mathrm{~mm}$ in women taking tibolone, and $5.5 \pm 2.5 \mathrm{~mm}$ in women receiving sequential HRT [11]. The endometrium in women receiving sequential HRT is $2 \mathrm{~mm}$ thicker and thus significantly thicker than in women taking tibolone or continuous HRT $(\mathrm{p}=0.0001)$. If the cut-off for patients without HRT is used for women receiving HRT, the diagnostic specificity for the detection of endometrial carcinoma is much lower, particularly for patients receiving sequential HRT [12].

\section{Carcinoma Risk Associated with Uterine Polyps $\nabla$}

The reported incidence of uterine polyps after menopause is between 13 and $17 \%$, depending on the study $[11,13,14]$. Most polyps are benign; however, a meta-analysis reported average rates for endometrial carcinoma of $4.47 \%$ in symptomatic postmenopausal women. In asymptomatic postmenopausal women with endometrial polyps, the carcinoma rate, according to the meta-analysis, was $1.51 \%$ [15].

\section{Early Detection in Patients Receiving Tamoxifen Therapy \\ $\nabla$}

Tamoxifen is a selective oestrogen receptor modulator and is much used in the therapy of breast cancer. The relationship between tamoxifen therapy and the development of pathological changes in the endometrial mucosa is well-known [16]. A higher rate of progression to atypical proliferations was demonstrated for postmenopausal women receiving tamoxifen therapy [17]. Based on the statistical analysis, the risk of developing endometrial carcinoma is 2.7 times higher for women receiving tamoxifen therapy [18]. However, in a recent study by Gao et al., transvaginal sonography done in 97 female patients only had a specificity of $63.6 \%$ and a sensitivity of $81.1 \%$. The positive predictive value was only $72.9 \%$ and the negative predictive value was $73.7 \%$ [19]. This emphasises the fact that transvaginal ultrasound is not able to detect pathological changes to endometrial mucosa with any high degree of certainty when performed during aftercare for tamoxifen therapy. Already in 1998, a study investigated 164 asymptomatic patients using transvaginal ultrasound. Although in this study, $54 \%$ of postmenopausal patients had an endometrial thickness of more than $5 \mathrm{~mm}$ measured sonographically, the imaging studies were not correlated with pathological changes to the mucosa [20]. The limited significance of transvaginal ultrasound findings in women receiving tamoxifen therapy was also confirmed in a study by Gerber et al. [21]. In another review article, all patients with endometrial carcinoma additionally had vaginal bleeding as a clinical sign of a serious endometrial pathology [22]. The value of transvaginal ultrasound consists in the presence of normal findings [23], although differing studies use differing threshold values. In general, most studies propose a cut-off of $5 \mathrm{~mm}$, even though studies to date have not been able to verify an increased sensitivity or specificity for this threshold value. A threshold value of $15 \mathrm{~mm}$ in women receiving tamoxifen therapy resulted in a higher sensitivity and better predictive values. In the study by Markovitch et al., the sensitivity was $37.9 \%$ but the specificity was $87.2 \%$; the positive predictive value was $63.0 \%$, and the negative predictive value was $70.2 \%$ [24]. While higher threshold values avoid unnecessary curettage procedures, a number of endometrial pathologies are not detected. When transvaginal ultrasound screening is done using a threshold value of $5 \mathrm{~mm}$ and the focus is on unremarkable ultrasound findings and not on the presence of endometrial pathologies, the sensitivity is $97 \%$ with a specificity of $35 \%$ [25].

\section{Conclusion \\ $\nabla$}

Vaginal ultrasound screening in asymptomatic patients for the early detection of endometrial carcinoma is not useful from a medical point of view, nor is it cost-efficient. Based on the data, widespread vaginal ultrasound screening will not reduce mortality but will result in a large number of unnecessary invasive procedures. However, even though the validity of transvaginal ultrasound for screening has currently not been proven, the method should still be an integral part of gynaecological examinations. But transvaginal ultrasound needs to be used with care to ensure that the benefits of this method, i.e. the potentially earlier detection of malignancy, are not outweighed by the disadvantages, i.e. unnecessary interventions for harmless findings.

\section{Conflict of Interest \\ $\nabla$}

None.

\section{Affiliations}

${ }^{1}$ Department of Obstetrics and Gynaecology, GPR Clinical Centre Ruesselsheim

2 Department of Obstetrics and Gynaecology, University of Saarland

${ }^{3}$ Department of Obstetrics and Gynaecology, Georg-August-University of Goettingen

${ }^{4}$ Department of Obstetrics and Gynaecology, Medical University of Vienna

${ }^{5}$ Department of Obstetrics and Gynaecology, University of Duisburg-Essen

${ }^{6}$ Department of Obstetrics and Gynaecology, Cologne University

\section{References}

1 Jacobs I, Gentry-Maharaj A, Burnell M et al. Sensitivity of transvaginal ultrasound screening for endometrial cancer in postmenopausal women: a case-control study within the UKCTOCS cohort. Lancet Oncol 2011; $12: 38-48$

2 Smith-Bindman R, Weiss E, Feldstein $V$. How thick is too thick? When endometrial thickness should prompt biopsy in postmenopausal women without vaginal bleeding. Ultrasound Obstet Gynecol 2004; 24: 558-565

3 Gerber B, Krause A, Muller $H$ et al. Ultrasonographic detection of asymptomatic endometrial cancer in postmenopausal patients offers no prognostic advantage over symptomatic disease discovered by uterine bleeding. Eur J Cancer 2001; 37: 64-71

4 Horwitz RI, Feinstein AR, Horwitz SM et al. Necropsy diagnosis of endometrial cancer and detection-bias in case/control studies. Lancet 1981; 2: 66-68

5 Smith-Bindman R, Kerlikowske K, Feldstein VA et al. Endovaginal ultrasound to exclude endometrial cancer and other endometrial abnormalities. JAMA 1998; 280: 1510-1517

6 Tabor A, Watt HC, Wald NJ. Endometrial thickness as a test for endometrial cancer in women with postmenopausal vaginal bleeding. Obstet Gynecol 2002; 99: 663-670

7 Clark TJ, Barton PM, Coomarasamy A et al. Investigating postmenopausal bleeding for endometrial cancer: cost-effectiveness of initial diagnostic strategies. BJOG 2006; 113: 502-510

8 Timmermans A, Opmeer BC, Khan KS et al. Endometrial thickness measurement for detecting endometrial cancer in women with postmenopausal bleeding: a systematic review and meta-analysis. Obstet Gynecol 2010; 116: 160-167 
9 Albring C, Baum E, Beckermann MJ et al. S3-Leitlinie: Hormontherapie in der Peri- und Postmenopause (HAT). AWMF-Leitlinien-Register 2009; Nr. 015/062

10 Lethaby A, Suckling J, Barlow D et al. Hormone replacement therapy in postmenopausal women: endometrial hyperplasia and irregular bleeding. Cochrane Database Syst Rev 2004; 3: CD000402

11 Van den Bosch T, Van Schoubroeck D, Ameye L et al. Ultrasound assessment of endometrial thickness and endometrial polyps in women on hormonal replacement therapy. Am J Obstet Gynecol 2003; 188: 1249-1253

12 Van den Bosch T, Coosemans A, Morina $M$ et al. Screening for uterine tumours. Best Pract Res Clin Obstet Gynaecol 2012; 26: 257-266

13 Dreisler E, Stampe Sorensen S, Ibsen PH et al. Prevalence of endometrial polyps and abnormal uterine bleeding in a Danish population aged 20 74 years. Ultrasound Obstet Gynecol 2009; 33: 102-108

14 Ferrazzi E, Zupi E, Leone FP et al. How often are endometrial polyps malignant in asymptomatic postmenopausal women? A multicenter study. Am J Obstet Gynecol 2009; 200: 235.e1-235.e6

15 Lee SC, Kaunitz AM, Sanchez-Ramos L et al. The oncogenic potential of endometrial polyps: a systematic review and meta-analysis. Obstet Gynecol 2010; 116: 1197-1205

16 Cohen I. Endometrial pathologies associated with postmenopausal tamoxifen therapy. Gynecol Oncol 2004; 94: 256-266

17 Garuti G, Cellani F, Centinaio G et al. Histopathologic behaviour of endometrial hyperplasia during tamoxifen therapy for breast cancer. Gynecol Oncol 2006; 101: 269-273

18 Singh MN, Stringfellow HF, Paraskevaidis E et al. Tamoxifen: important considerations of a multi-functional compound with organ-specific properties. Cancer Treat Rev 2007; 33: 91-100
19 Gao W, Zhang LP, Feng LM. Comparative study of transvaginal ultrasonographic and diagnostic hysteroscopic findings in postmenopausal breast cancer patients treated with tamoxifen. Chinese Medical J 2011; 124: 2335-2339

20 Bertelli G, Venturini M, Del Mastro L et al. Tamoxifen and the endometrium: findings of pelvic ultrasound examination and endometrial biopsy in asymptomatic breast cancer patients. Breast Cancer Res Treat 1998; 47: 41-46

21 Gerber B, Krause A, Müller $H$ et al. Effects of adjuvant tamoxifen on the endometrium in postmenopausal women with breast cancer: a prospective long-term study using transvaginal ultrasound. J Clin Oncol 2000; 18 : 3464-3470

22 Fung MF, Reid A, Faught Wet al. Prospective longitudinal study of ultrasound screening for endometrial abnormalities in women with breast cancer receiving tamoxifen. Gynecol Oncol 2003; 91: 154-159

23 Polin SA. The effect of tamoxifen on the genital tract. Cancer Imaging 2008; 8: 135-145

24 Markovitch O, Tepper R, Fishman A et al. The value of transvaginal ultrasonography in the prediction of endometrial pathologies in asymptomatic postmenopausal breast cancer tamoxifen-treated patients. Gynecol Oncol 2004; 95: 456-462

25 Weaver J, McHugo JM, Clark TJ et al. Accuracy of transvaginal ultrasound in diagnosing endometrial pathology in women with post-menopausal bleeding on tamoxifen. Br J Radiol 2005; 78: 394-397

Deutschsprachige Zusatzinformationen online abrufbar unter: www.thieme-connect.de/ejournals/toc/gebfra. 